Hydrol. Earth Syst. Sci., 11, 1703-1716, 2007

www.hydrol-earth-syst-sci.net/11/1703/2007/

(C) Author(s) 2007. This work is licensed

under a Creative Commons License.

\title{
Experimental analysis of drainage and water storage of litter layers
}

\author{
A. Guevara-Escobar, E. Gonzalez-Sosa, M. Ramos-Salinas, and G. D. Hernandez-Delgado
}

Universidad Autonoma de Queretaro. Santiago de Queretaro, Queretaro 76010, Mexico

Received: 23 May 2007 - Published in Hydrol. Earth Syst. Sci. Discuss.: 19 June 2007

Revised: 17 September 2007 - Accepted: 17 October 2007 - Published: 25 October 2007

\begin{abstract}
Many hydrological studies of forested ecosystems focus on the study of the forest canopy and have partitioned gross precipitation into throughfall and stemflow. However, the presence of forest litter can alter the quantities of water available for soil infiltration and runoff. Little information exists regarding the value of storage and drainage parameters for litter layers. Vegetation parameters of this kind are required in physically-based and lumped conceptual models to quatify the availabilty and distribution of water. Using a rainfall simulator and laboratory conditions two main objectives were investigated using layers of recently seneced poplar leaves, fresh grass or woodchips:

1) Effect of rain intensity on storage. With this respect we found that: maximum storage $\left(C_{\max }\right)$, defined as the detention of water immediately before rainfall cessation, increased with rainfall intensity. The magnitude of the increment was up to $0.5 \mathrm{~mm} \mathrm{~kg}^{-1} \mathrm{~m}^{-2}$ between the lowest $\left(9.8 \mathrm{~mm} \mathrm{~h}^{-1}\right)$ and highest $\left(70.9 \mathrm{~mm} \mathrm{~h}^{-1}\right)$ rainfall intensities for poplar leaves. Minimum storage $\left(C_{\min }\right)$, defined as the detention of water after drainage ceased, was not influenced by rainfall intensity. Repeated wetting-draining cycles or layer thickness have no effect on $C_{\max }$ or $C_{\min }$.

2) The evaluation of drainage coefficient for the Rutter model. This model was found accurate to predict storage and drainage in the case of poplar leaves, was less accurate for fresh grass and resulted in overestimations for woodchips.

Additionally, the effect of an underlaying soil matrix on lateral movement of water and storage of poplar leaves was studied. Results indicated that the soil matrix have no effect on $C_{\max }$ or $C_{\min }$ of the litter layer. Lateral movement of water in the poplar layer was observed at intermediate rainfall intensities (30.2 and $40.4 \mathrm{~mm} \mathrm{~h}^{-1}$ ), but not a the lowest or highest rates.
\end{abstract}

Correspondence to: A. Guevara-Escobar (guevara@uaq.mx)

\section{Introduction}

Interception loss is the amount of rainfall intercepted and subsequently evaporated from the vegetation. Many studies demonstrate that interception losses from tree canopies are very important in influencing the water yield of forested areas (Crockford and Richardson, 2000). Therefore, knowledge of the amount of water reaching the soil is essential to understand hydrological fluxes. Many reports consider that the drainage from the tree canopy (throughfall, $T_{h}$ ) and tree stems (stemflow, $S_{f}$ ) are the main sources of soil water. However, where forest floor litter has developed on the soil surface, the surfaces of the litter layer will intercept a proportion of both $T_{h}$ and $S_{f}$ (Putuhena and Cordery, 1996). If forest floor interception is also taken into account then the total amount of intercepted rainfall can be twice as much (Gerrits et al., 2007). On the other hand, omission of litter interception results in conservative estimates of total interception (Waring et al., 1980). Thus, hydrological models should incorporate adequately parameterized rainfall-interception representations of the canopy and the litter layer.

Forest floor litter is important in the water balance: Huber and Oyarzun (1992) reported litter interception as high as $8.9 \%$ of annual rainfall in a native evergreen forest in Chile. Balazs (1982) reported 18\% rainfall interception by the litter of Larix decidua (Mill.) and 7\% for Fagus sylvatica (L.) and Abies alba (Mill.). Consistent, but lower values (2-5\% of annual rainfall) had been measured for Populus tremuloides (Michx.) forests in North America (Helvey and Patric, 1965).

The difficulty of observing soil moisture routinely means that it is a property that needs to be modeled well, but in wooded lands the problem is not trivial. For instance, Keim et al. (2005) stressed the importance of throughfall spatial patterns; furthermore, patterns in throughfall water cannot directly be related to patterns in water content without knowledge of litter characteristics such as drainage (Raat et al., 2002). Lateral movement of water within the layer was

Published by Copernicus Publications on behalf of the European Geosciences Union. 
important for broad-leaf litter and much less for needle-leaf litter; thus flow channels spatially influenced storage capacity and drainage (Sato et al., 2004). Lateral movement of water in the litter layer would be another mechanism contributing to soil water variability. However, these results of lateral movement of water were obtained in the absence of a mineral soil.

\subsection{Bases for the study of storage and drainage}

Hydraulic mechanisms of the forest floor interception process are similar to the canopy interception process (Putuhena and Cordery, 1996). Similarly, storage capacity of litter layers can be defined as the depth of water stored or detained on the plant surface in still air (Horton, 1919). Two parameters of storage are important: transitory or maximum storage $\left(C_{\max }\right)$, which is water that would later drip and; residual or minimum storage $\left(C_{\mathrm{min}}\right)$, that depth of water removed only by evaporation ( Pitman, 1989; Putuhena and Cordery, 1996). Particularly, $C_{\min }$ represents the threshold of $T_{h}$ depth that result in drainage from the litter layer. Different representations of the storage-drainage relationship exists and many are efficient at modeling time-varying drip rates from the forest canopy (Keim and Skaugset, 2004). However, there are few reports incorporating any modeling for litter layers (Bristow and Campbell, 1986) although research from mulches is important (Bussiere and Cellier, 1994; GonzalezSosa et al., 2001; Findeling et al., 2003).

Boundary layer conductance and canopy storage capacity are the most important parameters in all models of rainfall interception loss by forest canopies. The variables that control evaporation are well studied but the processes of storage and drip have received less attention (Keim and Skaugset, 2004). Although many models predict interception empirically, physically or stochastically the models developed by Rutter (Rutter et al., 1971) and by Gash (Gash, 1979) are the most widely used. The Rutter model considers the tree canopy surfaces as a compartment for water storage and continuously simulates the depth of water retained. Rutter et al. (1971) described drainage in terms of canopy storage following an exponential function. Although this kind of equation does not conserve mass and predicts finite drip when the canopy is dry, it produces good fits to data over periods of time characteristic of canopy storage and drip (Keim and Skaugset, 2004). Only Bussiere and Cellier (1994) modeled water relations of a banana leaf mulch using the Rutter's model, but some required parameters used in that work were taken from a previous study of sugar cane mulch and not for a banana mulch (Bussiere and Cellier, 1993).

The mechanisms of rainfall interception depend on vegetation type, surface tension, mechanical activity as well as on the intensity and duration of rainfall (Zeng et al., 2000). Furthermore, live foliage elements can hold water by adsorption while absorption also occurs in the case of dead plant material or bark; these two processes modify the storage prop- erties of materials (Pitman, 1989). Also, decomposition of plant material would increase the proportion of water absorbed. The forest floor traditionally is divided into a upper horizon in which the origin of the material is identifiable and, the lower horizon in which the origin of the material is not recognizable. The water-holding capacity of the surface horizon essentially depends on the surface area of the material, analogous to storage on foliage. In the lower layers water is held by capillary force and the capacities increase (Waring et al., 1980). Many models of rainfall interception implicitly assume that foliage in the canopy is impervious. If water is absorbed by litter layers during a rainfall event, then the storage-drainage relationship proposed by Rutter et al. (1971) would not produce good fits.

Rainfall interception by litter layers is determined by the mass of litter on the ground, and its drying rate (Helvey and Patric, 1965). However, the mass of litter on the ground varies in space and time; species composition, wind, water, fire, animals and decay are important factors. Recent research in this field sampled the upper layer of the forest floor and analyzed interception under natural rainfall (Gerrits et al., 2007) or simulated rainfall (Pitman, 1989; TobonMarin et al., 2000; Sato et al., 2004). These studies indicate that storage capacity of litter layers increased linearly to litter mass (Putuhena and Cordery, 1996; Sato et al., 2004). Also Sato et al. (2004) demonstrated that rainfall intensity increased $C_{\min }$ and $C_{\max }$ of litter layers. For example $C_{\min }$ increased from 0.44 to $1.03 \mathrm{~mm}$ for Cryptomeria japonica (D. Don) and from 1.33 to $1.74 \mathrm{~mm}$ for Lithocarpus edulis (Nakai) when rainfall intensity was 5 and $50 \mathrm{~mm} \mathrm{~h}^{-1}$. Putuhena examined pine and eucalyptus litter layers and found a slightly higher $C_{\max }$ with higher rainfall intensity $\left(90-100 \mathrm{~mm} \mathrm{~h}^{-1}\right)$. On the other hand, Keim et al. (2006) studied branches of eight species and showed that storage was generally about $0.2 \mathrm{~mm}$ per leaf area higher at rainfall intensity of $420 \mathrm{~mm} \mathrm{~h}^{-1}$ than at $20 \mathrm{~mm} \mathrm{~h}^{-1}$. Yet, Calder (1986) proposed that storage capacity decreases with increased rainfall intensity. Whether or not storage increased with rainfall intensity has been debated (CarlyleMoses, 2004; Keim, 2004) and this needs further research.

Drainage, interception and storage are determined in most investigations reporting $C_{\min }$ and $C_{\max }$ by holding a litter sample by some sort of mesh with fine strands. However, this procedure was criticized by Helvey and Patric (1965) because the interface effect introduced when a mesh or another artificial barrier to natural drainage is placed between litter and soil, thus water filtering through the contained litter accumulates at the litter-container interface until surface tension is overcome. Instead, these authors proposed to collect litter samples from the forest floor during various stages of wetting and drying and weigh them to determine moisture content. However, transient drainage and storage can not be estimated by this method. Since the problem was surface tension, we hypothesized that the drainage response could be influenced by the negative pore pressure imposed by the 
neighboring soil. Also, it was possible that lateral movement of water would occur more likely if an underlying soil matrix was present.

\subsection{Objectives}

The purpose of present work was to a) investigate whether storage is increased with increasing rain intensity and; b) to obtain drainage coefficients and use them to predict storage according to the Rutter model. Additionally we were interested to know how repeated wetting-drying cycles influenced storage and the effect of an underlaying soil matrix on lateral movement of water and drainage.

\section{Material and methods}

Three tests with litter layers were carried out in a laboratory using a rainfall simulator. The data of drainage and storage obtained in the first test were compared with estimates from the Rutter model, which was calibrated with an independent dataset. An experimental approach was used to test and confirm the findings of other authors without the noise caused by the dynamics of litter decomposition, spatial distribution, interactions with grass growth, instrumentation in the field, or physical characteristics of throughfall, among others. All these factors are important, but must be studied with adequate manipulation to clearly assess a cause and effect relationship.

Poplar leaves was the main interest in the present work because poplar are multipurpose: these trees are easily incorporated in agroforestry systems, provide wood and nonwood products and are useful for erosion control. Whether litter floor should be conserved or harvested is an important decision, because leaf litter laying on pasture reduces pasture growth and may constitute a fire hazard but also plays a role in erosion control. To date only Helvey and Patric (1965) studied poplar litter interception but they did not explore the drainage characteristics of the litter.

\subsection{Rainfall simulator}

A computer-controlled Norton ladder-type rainfall simulator was used to produce various rainfall intensities (Sutherland and Ziegler, 2006). Figure 1 shows the scheme of the apparatus used. This simulator oscillates at varying speeds spraying an area $2 \mathrm{~m}$ wide. A $5 \mathrm{~m}$ aluminum ladder was used to support a pipe manifold, pressure gauges, spray boxes and drive train. A rotary axle mounts four Veejet $80-100$ nozzles spaced at $1.1 \mathrm{~m}$. The ladder was $2 \mathrm{~m}$ above the soil surface. The nozzles were supplied with water in sets of two; each set of nozzles had its own hose and pressure gauge. Each nozzle was enclosed in an aluminum spray box that regulates the spray for proper nozzle overlap and swath width. Each spray box had a window opening that could be electronically closed. The rotary axle positions the nozzles across the window whenever a signal was sent. A drain pipe collects excess water from the spray boxes; that was when the window was closed or when the nozzle moved away from the window during the rotation. The rotation was not constant, so the nozzles rotated twice, stopped for a few seconds, and then rotated again. A clutch brake started and stopped the boom as regulated by a signal from the computer. A small gear motor $(1 / 15 \mathrm{HP}, 100 \mathrm{rpm})$ drived the rotary axle and the clutch brake. A $4 \mathrm{HP}$ gasoline provided water pressure of $47.6 \mathrm{kPa}$ at the nozzles. A Qbasic program and a control box with a switch to turn on the oscillation axle simulated the selected rainfall intensity. Drop diameter was $1.8 \mathrm{~mm} \pm 0.2$ and the drop size distribution was similar within the range of rainfall intensities produced by the simulator. The spatial distribution of rainfall had a coefficient of variation of $14.4 \%$.

One sample container was positioned $2 \mathrm{~m}$ below each of the simulator's nozzles. This arrangement allowed the rainfall to reach terminal velocity. The containers had a circular area of $0.26 \mathrm{~m}^{2}$ and a height of $0.72 \mathrm{~m}$. A nylon mesh $(10 \mathrm{~mm}$ gap size) held the material samples inside the container. Outlets were fixed at the bottom of container to collect drainage. Simulated rainfall was applied using tap water.

\subsection{Material}

Three materials were tested: a) recently senesced poplar leaves (Populus nigra, L.); b) woodchips (Pinus sp.), which are a sawmill by-product and can be used as mulching material after clear-cut to prevent soil erosion and; c) fresh cut grass (Aristida divaricata, Humb. and Bonpl. ex Willd.), $0.2-0.3 \mathrm{~m}$ long, as a model of lodged tall grass. We selected these materials because they were readily available. Also, they were contrasting with regard to the physical characteristics of the surface and their capacity to absorb water.

Woodchips and poplar leaves were oven dried and then allowed to stabilize in the laboratory conditions. Fresh grass clippings were obtained every time from a nearby paddock. Average air dry bulk densities for woodchips, grass and poplar leaves were 60,48 and $15 \mathrm{~kg} \mathrm{~m}^{-3}$, their corresponding dry matter was 90,25 and $85 \%$, respectively.

Obtaining undisturbed samples was considered. However, enough random samples of the precise same mass or thickness was not feasible for the number of replicates needed. Mainly because the distribution of recently senesced poplar leaves in the field varies greatly from spot to spot and also wind plays a mayor role in its redistribution over time.

We considered that obtaining enough intact samples of poplar floor litter from the lower organic horizon and of the required thickness would be very difficult, may increase the variability of estimates and make hard to discern statistical differences. Therefore, woodchips were used as an example of "decomposed" material, given the exposure of the conducting vessels and tracheids of the xylem, broken cell walls and shattered fibers. The tracheids behave like true capil- 


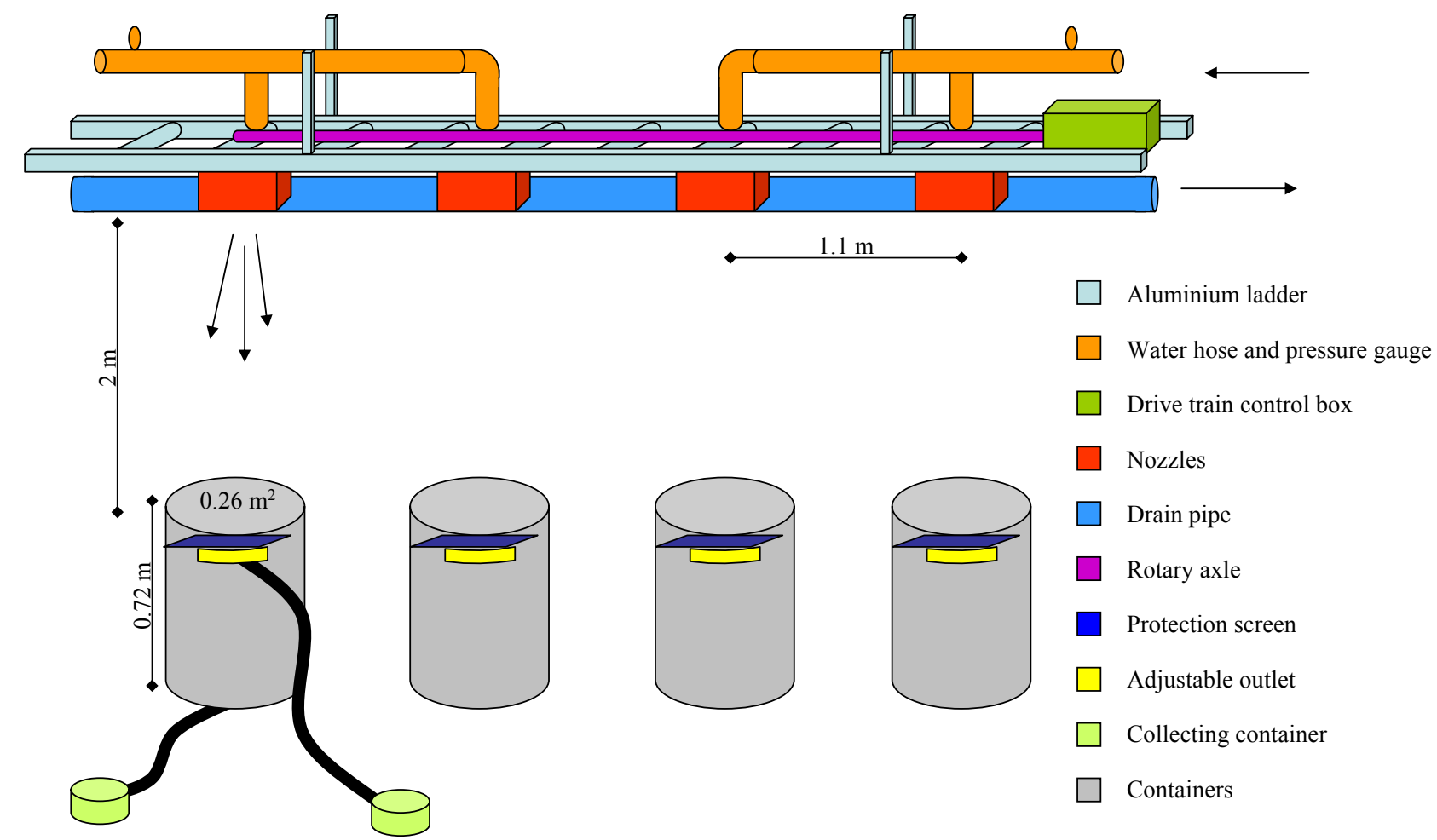

Fig. 1. Scheme of the rainfall simulator and experimental set-up. For clarity, the collecting containers and hoses are shown only for one container.

laries but the vessels are wider and capillary movement is less important. However, it must be keep in mind that water is drawn up the plant by transpiration according to the cohesion-tension theory and not by capillary movement.

\subsection{Test 1: Effect of rainfall intensity on storage}

For each material treatment, two layer thicknesses were tested: $z=0.05$ and $0.10 \mathrm{~m}$. The average fresh weight of the materials used with the $z=0.05 \mathrm{~m}$ treatment were: $3.85,1.92$ and $0.62 \mathrm{~kg} \mathrm{~m}^{-2}$ for woodchips, grass and poplar leaves, respectively; the corresponding values for $z=0.10 \mathrm{~m}$ treatment were: $9.23,5.77$ and $0.92 \mathrm{~kg} \mathrm{~m}^{-2}$.

Four rainfall intensities were tested: 9.8, 30.2, 40.4 and $70.9 \mathrm{~mm} \mathrm{~h}^{-1}$; this range of rainfall intensity was considered representative of natural conditions and was similar to the range of rainfall intensities used by Sato et al. (2004).

Treatments were allocated as a randomised complete block design, with the nozzles being the blocks. All material layers were replaced after one hour of rain simulation. One container, with no material layer, was left as a control for every rain simulation to measure incident rainfall $(P)$. Each material layer $\times$ layer thickness $\times$ rain intensity combination was replicated three times. The resulting 72 experimental units were allocated in 24 rainfall simulation runs.
2.4 Test 2: Effect of the litter layer-soil matrix interface on drainage and storage

After initial analysis of data presented in Sect. 2.3, the number of treatments was reduced. In the absence of a rainfall intensity $\times$ material interaction we judged that only one material was sufficient to test the effect of an underlaying soil matrix on lateral movement of water and drainage and, the effect of repeated wetting-drying cycles on storage. Therefore, only the poplar leaves were used in the tests presented in Sections 2.4 and 2.5. Here the treatments tested were: no layer and two layer thicknesses $z=0.05$ and $0.10 \mathrm{~m}$ and the four rainfall intensities described in Sect. 2.3.

In this test the nylon mesh was overlaying a $300 \mathrm{~mm}$ layer of sieved, dried and compressed sewage sludge. Sewage sludge was selected because the granular texture of this material allowed constant infiltration of water and because: a) this material did not collapse after repeated rainfall simulations or when saturated and the pore size distribution was preserved; b) a control with a soil matrix, but without an overlaying litter layer, was included in the experimental design; c) replacing the soil matrix between runs was expensive and cumbersome. If a common soil was used (vertisols in our region), clogged pores and water ponding in the surface would be a problem, even with soils of little clay content. The rest of the 
container was packed with sand $(0.2 \mathrm{~mm}$ diameter $)$ under the sewage sludge and the leaf layers. Oven dry bulk densities of the packed media were 0.95 and $2.0 \mathrm{Mg} \mathrm{m}^{-3}$ for sewage sludge and sand.

Runoff $(R)$ was measured as the drainage from an outlet fixed at the interface between the material layer and the soil matrix. These outlets were adjustable in height and had a protecting screen to avoid the collection of incident rainfall. This runoff would correspond to rapid subsurface flow production through the leaf layer, sometimes called the "thatched roof effect" (Weiler and McDonnell, 2004) or pseudo-Hortonian overland flow, whereby differences in saturated hydraulic conductivity at the organicmineral soil boundary create lateral flow in the near-surface horizon (Helvey and Patric, 1965; Brown et al., 1999).

The soil matrix in each container was maintained near saturation. Prior to each simulation run, one hour- $42 \mathrm{~mm} \mathrm{~h}^{-1}$ rainfall was applied to the soil matrix in the containers until constant drainage was obtained. All leaf layers were replaced by fresh material after one hour of rain simulation.

\subsection{Test 3: Effect of wetting drying cycles on drainage and storage}

In this test, we used poplar leaves masses of $0.2,0.4$, $0.6,0.8$ and $1.0 \mathrm{~kg} \mathrm{~m}^{-2}$ and applied a rainfall intensity of $30.2 \mathrm{~mm} \mathrm{~h}^{-1}$. Three rain-drain cycles were obtained for each sample. Rain was applied for one hour, drainage was allowed for one hour, rainfall was applied again for one hour, drainage was allowed for two hours, rainfall was applied for one hour once more and then, allowed to drain. Treatments were allocated as a randomised complete block design, with the nozzles being the blocks. The experiment was replicated four times. The leaf layers were replaced after each replicate rain-drain cycle.

\subsection{Measurements}

Measurements were made for initial and final layer mass using an electronic balance. The weight of the water detained by the nylon mesh was subtracted to correct the original data. Rainfall, temperature, relative humidity, wind speed and air pressure were measured using a WXT510 multi-sensor (Vaisala, Helsinki, Finland). This sensor was connected to a CR1000 datalogger (Campbell Scientific Ltd., Shepshed UK), averaging at a 1 min time step. The sensor measured rainfall with a resolution of $0.01 \mathrm{~mm}$. Drainage was recorded during and after the rainfall simulation. Drainage was weighed every $5 \mathrm{~min}$ in tests presented in Sects. 2.3 and 2.4, while in Sect. 2.5 the drainage outlets were individually routed into tipping-bucket gauges and recorded once per minute. These TE-525LL-L (Texas Electronics Inc., Dallas TX) gauges were calibrated to record $0.254 \mathrm{~mm}$ per tip. The storage $(C[\mathrm{~mm}])$ was indirectly calculated as:

$\frac{\mathrm{d} C}{\mathrm{~d} t}=P-D-R$.

where $P\left[\mathrm{~mm} \mathrm{~h}^{-1}\right]$ was the amount of rainfall supplied from the simulator and $D\left[\mathrm{~mm} \mathrm{~h}^{-1}\right]$ and $R\left[\mathrm{~mm} \mathrm{~h}^{-1}\right]$ the amount of drainage collected from the outlets of each container. Two different interception storage capacities were determined for each sample: $C_{\max }[\mathrm{mm}]$, the maximum storage of the material layer calculated as the amount of water detained in the sample immediately before the rainfall simulation ceased; $C_{\min }[\mathrm{mm}]$, the minimum storage of the material layer calculated as the amount of water detained after free drainage had ceased (Putuhena and Cordery, 1996). When adequate, storage was normalized by area and mass $\left(\mathrm{mm} \mathrm{kg}^{-1} \mathrm{~m}^{-2}\right)$, in order to compare the different treatments and to those values reported in the literature.

\subsection{Estimation of model parameters}

The elements of the litter layers do not form a connected network and cannot allow water movement by capillarity; movement of water only can take place by dripping of intercepted water and penetration of rainfall through gaps (Bussiere and Cellier, 1994). Therefore, the drainage process was modeled according to Rutter et al. (1971). The resulting predictions of drainage and storage were compared with the experimental data.

Briefly, the model considers the changes in water stored within the vegetation as determined by the balance between $P, D$ and evaporation $\left(E\left[\mathrm{~mm} \mathrm{~h}^{-1}\right]\right)$ from the water stored within a vegetation compartment:

$\frac{\mathrm{d} C}{\mathrm{~d} t}=\left(1-f_{g}\right) \times P-k \times e^{b \times\left(\frac{C}{S}\right)}-\left(E\left(\frac{C}{S}\right)\right)$.

where $t$ is time; $f_{g}$ is the ratio of rainfall that passes freely through the spaces of canopy vegetation (porosity). The exponential term corresponds to the rain drained by the vegetation canopy (dripping or drainage), in which $k$ and $b$ are vegetation characteristic parameters, also known as percolation and drainage parameters. The $S[\mathrm{~mm}]$ term corresponds to maximum storage of the reservoir and can be estimated by linear regression of the type:

$T_{h}=b_{0} \times P+b_{1}$.

for $P>P_{S}$, where $P_{S}$ is the amount of rainfall needed to reach saturation and $T_{h}\left[\mathrm{~mm} \mathrm{~h}^{-1}\right]$ is throughfall (Rutter et al., 1971). The parameters $b_{0}$ and $b_{1}$ results in estimates of the ratio of evaporation to rainfall and $S$, respectively (Klaassen et al., 1998). Drainage was predicted using the relation between $D$ and $C$ (Bussiere and Cellier, 1994):

$D=k \times \exp (b C)$.

Evaporation was considered negligible, according to the environmental measurements made during the simulation runs 

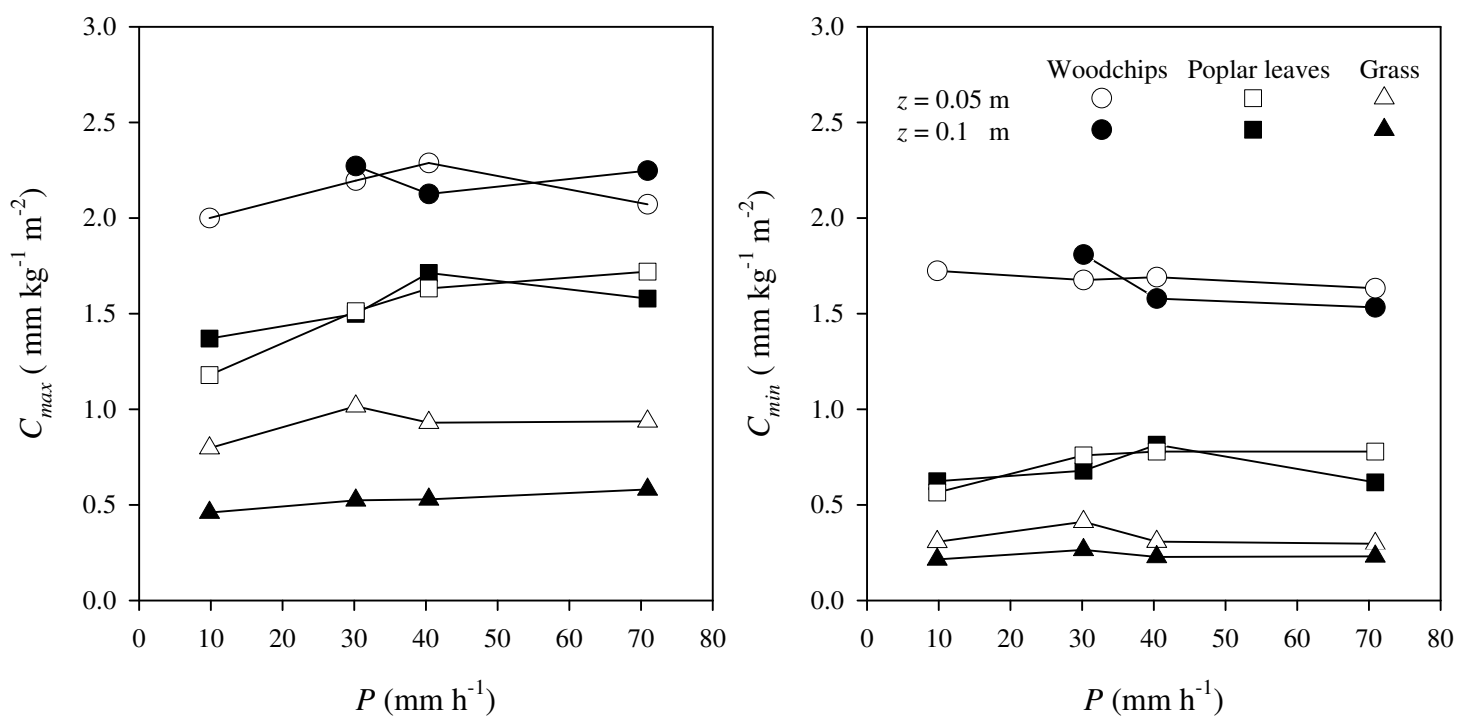

Fig. 2. Effect of rainfall $(P)$ of various intensities on $C_{\max }$ and $C_{\min }$ of three materials and two layer thicknesses and without an underlying soil matrix.

and because the experiment was conducted in a laboratory environment and wind speed was zero. These conditions were chosen because the interception fraction and the storage capacity parameter are better identified when evaporation is low (Vrugt et al., 2003). The parameters $k\left[\mathrm{~mm} \mathrm{~s}^{-1}\right]$ and $b\left[\mathrm{~mm}^{-1}\right]$ were estimated independently from the tests described above. Data for this model was obtained using a layer thickness of $z=0.05 \mathrm{~m}$ and a rainfall intensity of $70 \mathrm{~mm} \mathrm{~h}^{-1}$. This rainfall rate satisfied $P \geq P_{S}$. Three materials were used: woodchips, poplar leaves and fresh grass. Three replicates were obtained for each treatment combination. The container used had a circular area of $0.1 \mathrm{~m}^{2}$, and its bottom had nylon mesh $(10 \mathrm{~mm}$ gap size $)$ to hold the material in place. The container was weighted constantly by an electronic balance. The container frame avoided the contact between the mesh and the balance plate. Drained water from the base of the material layer and the container weight were recorded every minute.

\subsection{Statistical analysis}

Data were analyzed as a randomised block design using the general linear model procedure (GLM) of SAS (SAS Institute, Cary, NC, USA). Significance of all pre-planned comparisons was obtained using the Tukey test (Steel and Torrie, 1980). Models were fitted using the GLM procedure within SAS to establish the significance of regressions. The minimum level for significance was set at $\mathrm{p} \leq 0.05$.

\section{Results and discussion}

\subsection{Test 1: Effect of rainfall intensity on storage}

The materials tested differed in $C_{\max }$ and $C_{\min }$ (Fig. 2). Maximum storage increased with increasing rainfall intensity in the case of poplar leaves $(p \leq 0.05)$. This relation was not as evident for the fresh grass or woodchips. Differences in $C_{\max }$ between the layer thicknesses were more evident for fresh grass. Small differences in $C_{\max }$ between layer thicknesses were identified for woodchips and poplar leaves, but this did not occurr for all rainfall intensities. The $9.8 \mathrm{~mm} \mathrm{~h}^{-1}$ rainfall intensity was not sufficient to saturate the woodchips layers and therefore, this simulation run was not considered in the results.

The performed analysis of variance explained 97.6 and $99.3 \%$ of the variation of $C_{\max }$ and $C_{\min }$ due to the effects of layer thickness, material and rainfall intensity. This indicated that the experimental error, due to other factors, was small.

Some authors indicate that the storage, when free drainage has ceased after rain $\left(C_{\min }\right)$, is more important for moisture dynamics of the forest floor than $C_{\max }$ because gravitational water is drained 30 minutes after the end of rainfall (Putuhena and Cordery, 1996; Sato et al., 2004). However, $C$ close to $C_{\max }$, represents an amount of water that dampens and lags rainfall intensity and is dynamic in nature (Keim et al., 2006). In the present work, an increase of $C_{\max }$ was related to rainfall intensity. Considering the case of poplar leaves and the rainfall intensities of 9.8 and $70.9 \mathrm{~mm} \mathrm{~h}^{-1}$, the magnitude of the increments were 0.2 and $0.5 \mathrm{~mm} \mathrm{~kg}^{-1} \mathrm{~m}^{-2}$ for layer thicknesses of 0.05 and $0.1 \mathrm{~m}$. Keim et al. (2006) 
examined branches of eight species and found that storage was $0.2 \mathrm{~mm}$ per leaf area greater at rainfall intensity of 420 than at $20 \mathrm{~mm} \mathrm{~h}^{-1}$.

Keim et al. (2006) proposed that increased storage proportional to rainfall intensity results from the balance between the addition of water and the dislodging of the existing storage. Dominant forces that contribute to storage are gravity and cohesion. Sato et al. (2004) argued that water storage capacity of litter layers was proportional to the litter mass regardless of layer thickness; and this signified that the storage of the litter layer may not be determined by the "capillary water" held in the gaps created between litters, but by the "adhesion water" held by each litter surface. However, viscosity is another force that might influence water detention by some surfaces, particularly rough surfaces; i.e. those with a high ratio between the total surface area and the geometric surface area (termed roughness factor or rugosity). The apparent contact angle is also influenced by the surface roughness, because air entrapped at surface irregularities enlarges the contact angle.

The increments in the value of $C_{\max }$ were lower than the increases reported by Sato et al. (2004). Keim et al. (2006) suggested that morphological characteristics of vegetation may play a role in this process and they provided a conceptual mechanical model of canopy storage during rainfall that includes the concepts of static storage and dynamic storage to account for intensity-driven changes in storage. Sato et al. (2004) described the material used as intact samples collected from the field of relatively undecomposed litter layer, they also mentioned that the $C$. japonica shoot is composed twigs and needles, with 3 to 5 twigs and curved, awl-shaped needles while L. edulis is composed of a broad, oblong-shaped leaf about $6-13 \mathrm{~cm}$ long and $2-4 \mathrm{~cm}$ wide, with a leathery texture. Putuhena and Cordery (1996) also reported different storage for pine and eucalypt forest floor, but only slightly higher maximum water detention was observed for the higher rainfall intensity. We agree with Keim et al. (2006) with respect to increased storage related to the physical characteristics of the foliage (and branches). In our study, the poplar leaves and the shoot and leaves of grass were glabrous (hairless) and, possibly drainage was faster (and storage lower) from these surfaces than from hairy leaves (with trichomes) used by Sato et al. (2004). Leaf trichomes have been considered as an important ecophysiological factor contributing to an increase in the leaf boundary layer resistance. Trichomes may modify the contact angle, capillary radius and surface tension, thus reducing water loss.

The effect of rainfall intensity on $C_{\min }$ was not very clear, $C_{\text {min }}$ of woodchips tended to decrease with increasing rainfall intensity while for poplar leaves and fresh grass, $C_{\min }$ remained fairly constant with respect to rainfall intensity. Also, there was no effect of layer thickness on $C_{\min }$.

The water storage of poplar leaves and fresh grass layers after draining ranged from 0.4 to $0.7 \mathrm{~mm}$, when expressed as the weighted mean storage per unit of dry mass $\left(\mathrm{mm} \mathrm{kg}^{-1} \mathrm{~m}^{-2}\right)$. These values were lower than those reported previously on the same basis: water storage after drainage of Pinus radiata slash was $0.7 \mathrm{~mm}$ (Kelliher et al., 1992); Putuhena and Cordery (1996) found that $C_{\min }$ was 0.96 and $1.12 \mathrm{~mm}$ for coniferous and eucalyptus litter types; Tobon-Marin et al. (2000) for Amazonian rainforest litter reported $1.5 \mathrm{~mm}$ storage after drainage; the $C_{\min }$ reported by Sato et al. (2004) for coniferous and broadleaved litter types were in the range of $0.27-3.05 \mathrm{~mm}$ and; measured $C_{\min }$ of bracken litter was $1.67 \mathrm{~mm}$ (Pitman, 1989). The discrepancy with the results of the present work was explained by the different materials analyzed but also could be attributed to the different methodological approaches to simulate rainfall. Pitman (1989) used a fine spray at a rate of $150 \mathrm{~mm} \mathrm{~h}^{-1}$ and wetted the litter sample until constant weight was obtained; Sato et al. (2004) used a pressurized raindrop simulator at rates of 5,10 and $50 \mathrm{~mm} \mathrm{~h}^{-1}$ during three hours; Putuhena and Cordery (1996) used a rainfall simulator that produced drops starting from zero velocity and the falling drops then stroked a splash screen $2 \mathrm{~m}$ above the sample tray that produced drops 2-3 $\mathrm{mm}$ in diameter. Tobon-Marin et al. (2000) manually sprinkled water until water excess was observed and the samples showed to be completely wet.

\subsection{Test 2: Effect of the litter layer-soil matrix interface on drainage and storage}

An interesting aspect related to the litter-soil interface is lateral movement of water which is important for the modeling of hydraulic connectivity and overland flow. In this test the objective was to evaluate pseudo-Hortonian overland flow and this occurred only when the rainfall intensity was 40.4 and $70.9 \mathrm{~mm} \mathrm{~h}^{-1}$; this accounted for 0.4 and $0.8 \%$ of drainage.

Drainage flow originated from the bottom of the containers in the tests reported in Sects. 3.1 and 3.2 are presented here together because they show similar trends although there were some differences (Fig. 3, Fig. 4). The drainage rate stabilized to maximum rates equivalent to the applied rainfall intensity approximately after $15 \mathrm{~min}$ when there was no underlying soil matrix below the leaf layers. When the soil matrix and the leaf layer were considered (for poplar leaves only), the drainage rate stabilized after 20 to $40 \mathrm{~min}$; depending on rainfall rate (Fig. 4). The results of this test showed a damping effect on drainage of the poplar leaves layers at intermediate rainfall intensities. In particular, the $z=0.1 \mathrm{~m}$ layer delayed drainage in comparison with the no layer treatment (Fig. 4 b and c).

With the exception of the simulations involving the $9.8 \mathrm{~mm} \mathrm{~h}^{-1}$ treatment, drainage initiated almost instantaneously in the absence of the leaf layer. This condition indicated that the soil matrix was very close to saturation.

The initial drainage rate for the poplar litter in Fig. 3 was very similar regardless of layer thickness or rainfall intensity. In Fig. 4, the drainage rate was different between the two 

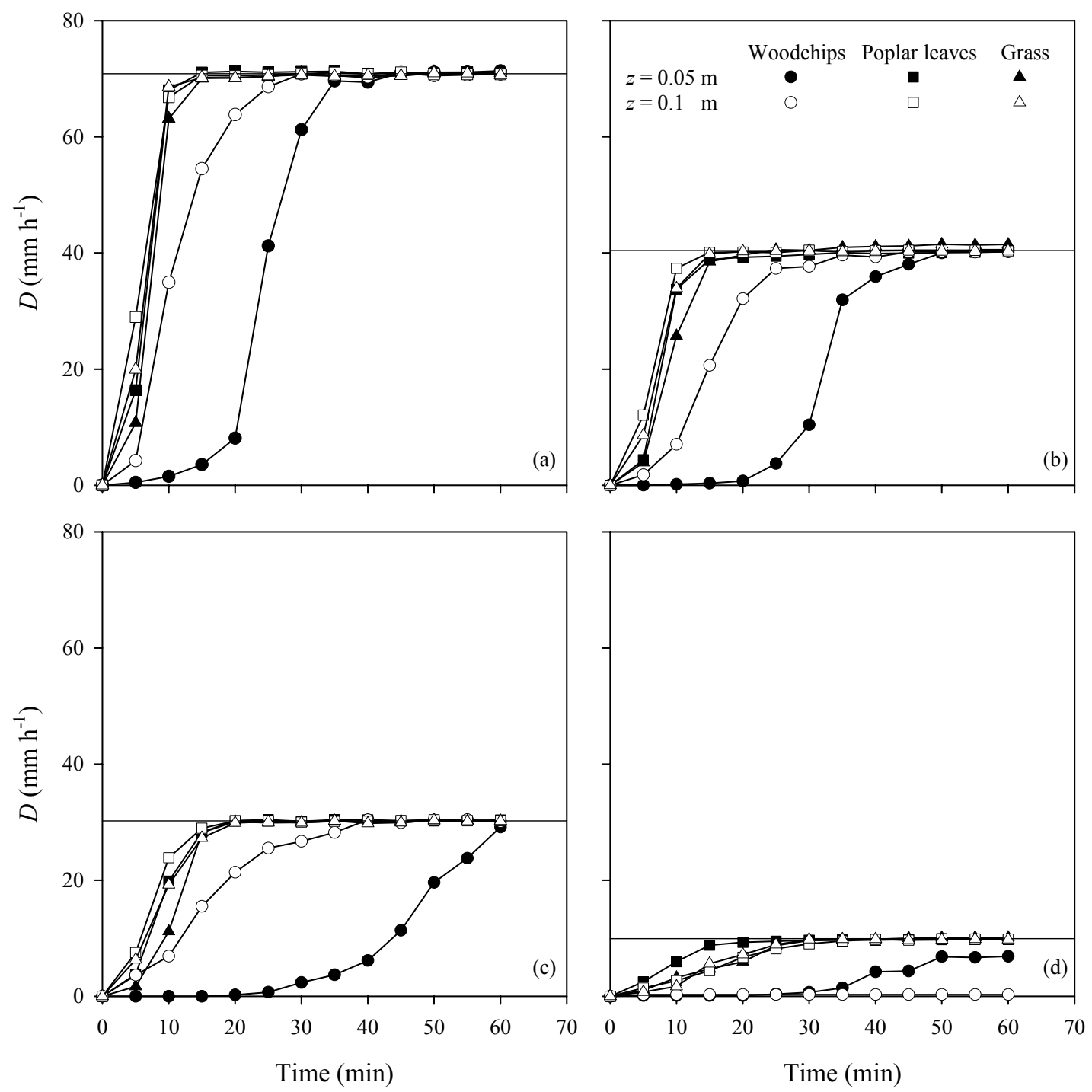

Fig. 3. Time trend of drainage $(D)$ of three materials and two layer thicknesses and without an underlying soil matrix. Graphs correspond to rainfall intensities: (a) 70.9 , (b) 40.4 , (c) 30.2 , and (d) $9.8 \mathrm{~mm} \mathrm{~h}^{-1}$.

layer thicknesses evaluated $(0.05$ and $0.10 \mathrm{~m})$. However, the combined effect of the poplar litter and the soil matrix must be taken into account.

Drainage started earlier, when a poplar layers were not present, and drainage rate was initially higher when rainfall intensity was 30.2 or $40.4 \mathrm{~mm} \mathrm{~h}^{-1}$ (Fig. $4 \mathrm{c}$ and b). Whereas when the rainfall intensity was low or high, the drainage rate was similar regardless of the layer thickness or the presence or absence of the poplar litter (Fig. $4 \mathrm{~d}$ and a). This suggested that the poplar litter had a higher effect on drainage at the intermediate rainfall intensities and we related this to the lateral movement of water observed at these rainfall intensities.

When rainfall intensity was $9.8 \mathrm{~mm} \mathrm{~h}^{-1}$ and a soil matrix and poplar litter were present, drainage was low during the first part of the experiment indidcating that the wetting up the layer was slow. After $30 \mathrm{~min}$ drainage increased and at $45 \mathrm{~min}$ attained rates higher than $9.8 \mathrm{~mm} \mathrm{~h}^{-1}$. This result could indicate that $C$ was higher than $C_{\max }$ during the first $30 \mathrm{~min}$ and then decreased. The result also suggested increased surface tension at the soil-litter interface or positive pore pressure near the surface of the soil matrix. This view was supported by the results when the soil matrix was absent because this drainage response was not observed. It was possible that this effect also occurred at the higher rainfall rates of 30.2 or $40.4 \mathrm{~mm} \mathrm{~h}^{-1}$ but was masked by lateral movement of water.

On the other hand, at the highest rainfall intensity of $70.9 \mathrm{~mm} \mathrm{~h}^{-1}$ water flow was very fast and the leaf layer had 

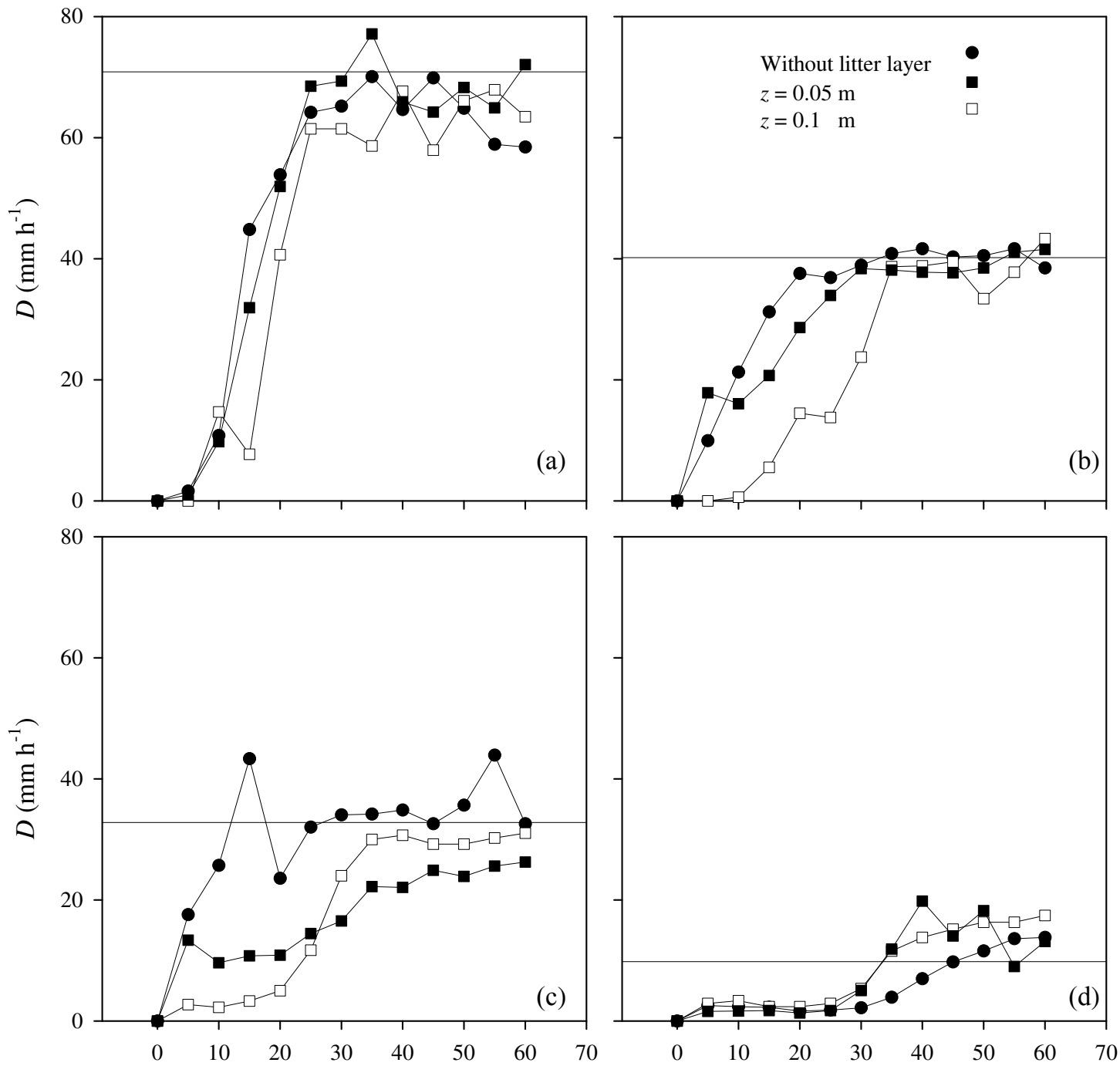

Time (min)

Time (min)

Fig. 4. Time trend of drainage $(D)$ of layers of poplar leaves of two thicknesses and with an underlying soil matrix. Graphs correspond to rainfall intensities: (a) 70.9, (b) 40.4, (c) 30.2 , and (d) $9.8 \mathrm{~mm} \mathrm{~h}^{-1}$.

little effect on reducing drainage or on lateral redistribution of water, probably because water channel connectivity was achieved early during the process.

Sato et al. (2004) reported increased lateral drainage when litter mass increased in the case of the broad leaf L. edulis. This result was reached by supplying the rainfall into only a central part of the litter surface, approximately one-third of the surface area of a $16 \times 24 \mathrm{~cm}$ container, drainage was collected from the central and lateral parts of the tray. They concluded that the broad-leaf litter can intercept more rainwater than the needle-leaf litter of $C$. japonica, because larger amounts of rainwater spread within the flat-type litter layer of the former and therefore, was more likely to have wet surfaces than the latter. The results of this test were in agreement although the magnitude was much lower. It was possible that both, leaf shape and the soil matrix interface play a role in the spread of water laterally and a more uniform, wetting front of the litter surfaces. Nevertheless, the effect of lateral movement and leaf shapes on runoff in a slope still remains to be determined.

No difference was found for the values of total drainage between the tests reported in Sects. 3.1 and $3.2(\mathrm{p} \leq 0.05)$. Also, the values of $C_{\max }$ were similar for the poplar leaves layers and the corresponding rainfall intensities. In presence of a soil matrix, the values of $C_{\max }$ were obtained as the difference by weight of the leaf layer when the rainfall simulation was stopped and the initial weight of the sample. Whereas in the absence of a soil matrix, $C_{\max }$ was the re- 


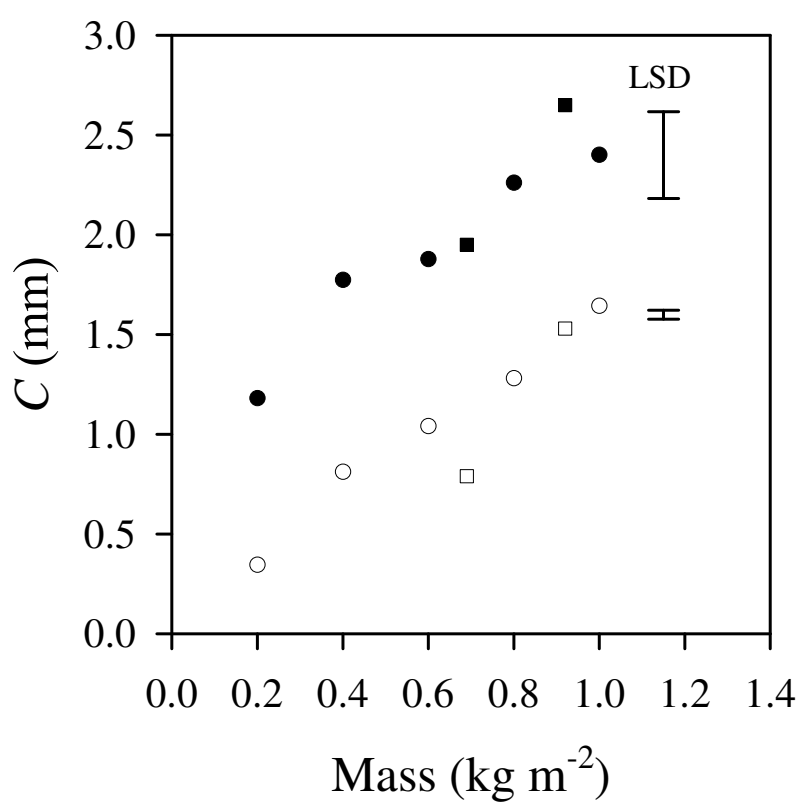

Fig. 5. Effect of layer mass on maximum storage (closed symbols) and minimum storage (open symbols) of poplar leaves. Squares and circles correspond to values reported in Sects. 3.1 and 3.2 under a rainfall intensity of $30.2 \mathrm{~mm} \mathrm{~h}^{-1}$. The least significant difference (LSD) corresponds to $\mathrm{p}<0.05$ and Tukey test.

sult of the water mass balance (Eq. 1). This result suggested that the soil matrix had no effect on the final maximum storage of the leaf layer. However, the observed lateral flow of water and the lower drainage rate during the first part of the experiment (at rates lower than $70.9 \mathrm{~mm} \mathrm{~h}^{-1}$ ) suggested that further studies of the leaf layer-soil matrix interface must be researched to evaluate transient storage.

Throughfall drop size distributions (DSD) were not considered in the present study or in previous studies of storage and drainage by litter layers. Free throughfall, splash droplets and drip contribute to the DSD, and in turn, the DSD is modified by wind, the species capacities to produce large drips and rainfall intensity (Nanko et al., 2006). The energy of throughfall can be up to 1.8 times of that of rainfall and under some types of forest management, soil cover removal could increase soil erosion by 10 to 100 times; while tree canopy removal without disturbing soil cover increases soil erosion rate very little (Wiersum, 1984). Because the kinetic energy of throughfall depens on DSD and canopy height, the results presented here were more representative of a leafless canopy.

The experimental setting and procedures were not ideal to test differences in drainage and the criticism of Helvey and Patric (1965), mainly because the mesh was present and was required to hold the sample in place. Also, we choose a quasi saturated condition of the soil matrix in order to reduce

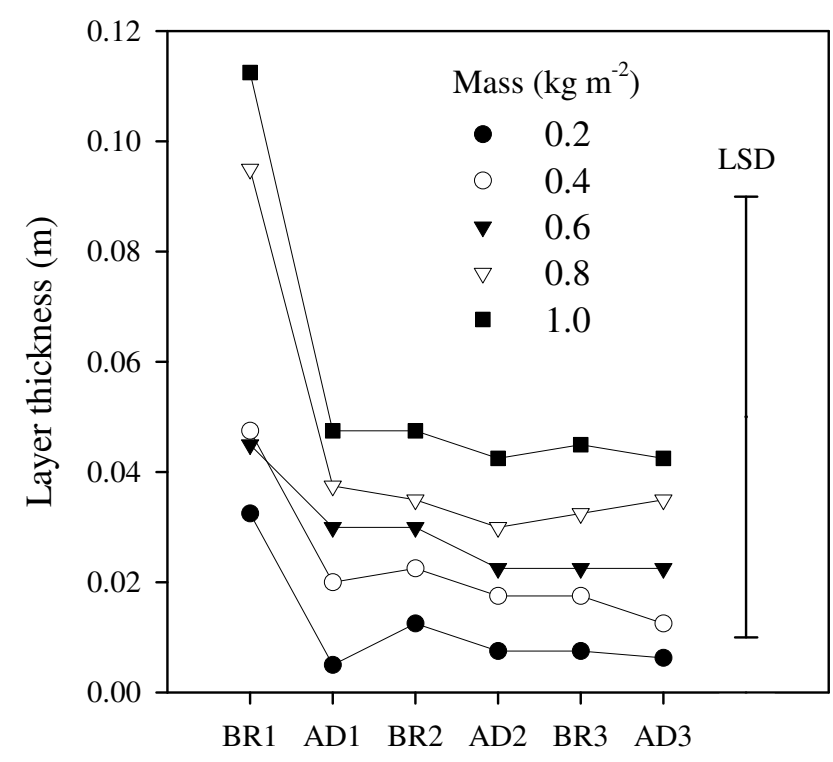

Measuring point during the simulation cycle

Fig. 6. Effect of litter mass on layer thicknesses at various points during the simulation cycle in Test 3: BR1, BR2 and B3, before rain started in simulation number 1, 2 and 3 respectively; AD1, AD2, AD3, after drainage in simulation number 1, 2 and 3. The least significant difference (LSD) corresponds to $\mathrm{p}<0.05$ and Tukey test.

the lag in the drainage response and decrease the variability arising from different water content conditions between runs. Thus, capillary movement in the soil matrix was likely during the initial phases of the experiment and afterwards, water conductivity might be limited to some extend by air bubbles in the soil matrix. We could not determine when saturated flow started, although we suspect that for most of the experimental runs it occurred. Monitoring the wetting front and hydraulic conductivity by means of a tracer and time domain reflectometry would be highly desirable to clarify this and to model transient drainage flow exceeding an steady state rate.

\subsection{Test 3: Effect of wetting drying cycles on drainage and storage}

Figure 5 shows the scatter diagram of rainfall storage versus poplar leaf mass for rainfall intensity of $30.2 \mathrm{~mm} \mathrm{~h}^{-1}$. These values correspond to the first rain-drain cycle. Data showed that storage increased with increasing leaf mass. However, the value of $C_{\min }\left(\mathrm{mm} \mathrm{kg}^{-1} \mathrm{~m}^{-2}\right)$ remained constant after three rain-drain cycles $(\mathrm{p} \leq 0.05)$. Although the layers decreased in thickness (Fig. 6), no statistical difference between the simulation runs of the same sample were found for their mean value of storage. These results suggested that the compaction of the litter layer had little effect on the value of $C_{\min }$. 

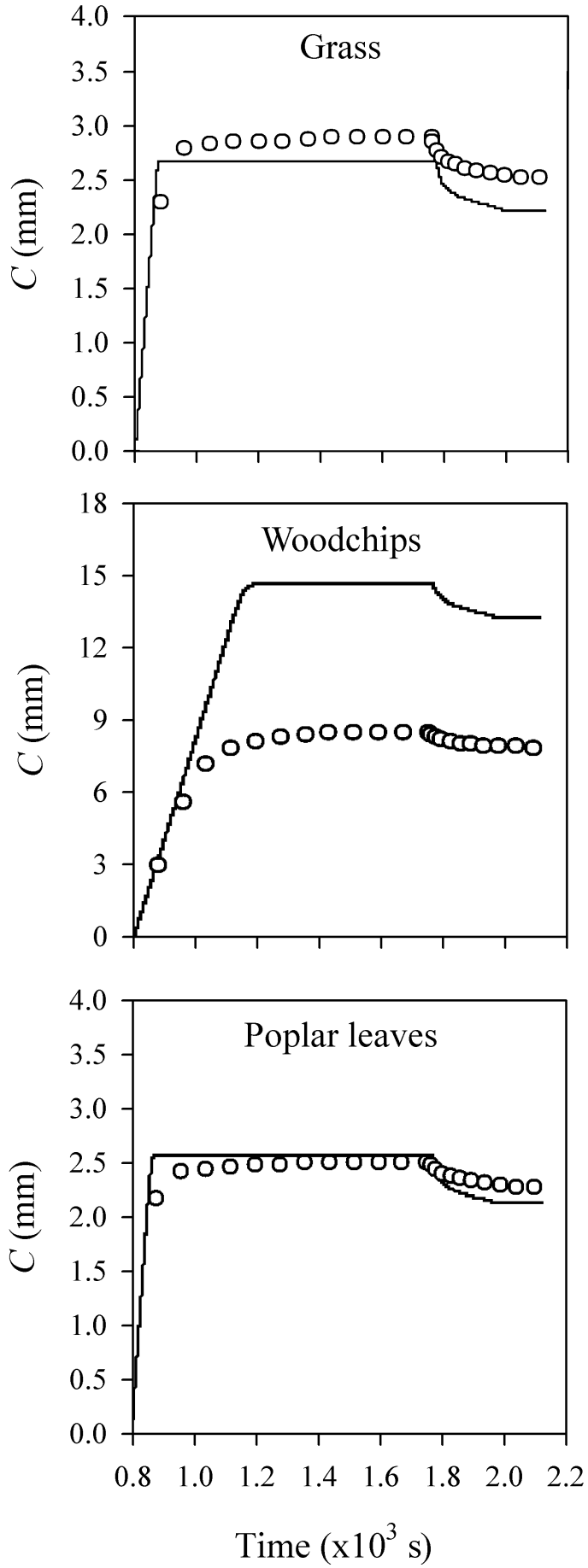

Fig. 7. Time trends of measured (open circles) and modeled (solid line) storage $(C)$ of $z=0.05 \mathrm{~m}$ layers of three materials under a rainfall simulation of $40.2 \mathrm{~mm} \mathrm{~h}^{-1}$.

In this test, three consecutive rain simulation runs were carried on; each time $C_{\max }$ and $C_{\min }$ were measured but no statistical differences were found between the storage calculated for consecutive simulation runs. Similar results were
Table 1. Means for the parameters of the model $\ln (D)=k+b C$ to predict drainage.

\begin{tabular}{lllll}
\hline Material & $\begin{array}{l}b \\
\mathrm{~mm}^{-1}\end{array}$ & $\mathrm{SE}^{1)}$ & $\begin{array}{l}k^{2)} \\
\mathrm{mm} \mathrm{s}^{-1}\end{array}$ & $\mathrm{SE}$ \\
\hline Woodchips & 2.15 & 0.13 & 0.00256 & 0.005 \\
Grass & 8.83 & 1.07 & 1.09265 & 1.689 \\
Poplar leaves & 9.92 & 0.20 & 0.69977 & 0.054 \\
\hline
\end{tabular}

1) Standard error of the mean.

2) $\times 10^{-12}$.

reported by Sato et al. (2004). This suggested that during the rain-drain cycle $(7 \mathrm{~h})$ recently senesced poplar leaves absorbed little water. Therefore, the values of $C_{\min }$ obtained in this test were representative of the quantity required to wet all surfaces (Rutter et al., 1971). If the surface could absorb water between runs, then $C_{\min }$ would be higher for each run until a steady state-weight was reached, as in the case reported by Pitman (1989). More fragmented materials (Pitman, 1989), as the woodchips tested in the present work, would have a higher absorption rate. Water absorption could explain the poor relationship between measured and modeled drainage and the overestimation of $C$ shown in Fig. 7 for woodchips. In general, data showed that the relationship proposed by Rutter et al. (1971), between drainage and storage holds for poplar leaves and fairly for fresh grass.

\subsection{Estimation of model parameters}

Three simulations using a $70 \mathrm{~mm} \mathrm{~h}^{-1}$ rainfall intensity were made for each material to obtain the relationship between $D$ and $C$, the average values of $b$ and $k$ parameters are presented in Table 1. The poplar litter had the fastest drainage as indicated by the value of $b$ and was followed by fresh grass and woodchips. Bussiere and Cellier (1993) reported $2.3 \mathrm{~mm} \mathrm{~s}^{-1}$ for $b$ for a sugar cane mulch and, Rutter et al. (1971) reported $3.7 \mathrm{~mm} \mathrm{~s}^{-1}$ for Pinus nigra. Other authors usually estimated $b$ and $k$ by extrapolating Rutters original values.

Agreement between observed and modeled values of $D$ was better for the poplar leaves layers $r^{2}=0.97$, Fig. 8). As an example, the time trends of observed and modeled $C$ are presented using the data obtained in Section 3.1 for a rainfall intensity of $40.2 \mathrm{~mm} \mathrm{~h}^{-1}$ (Fig. 7). Figure 8 suggested that $b$ and $k$ were independent of rainfall intensity and layer thickness because these parameters efficiently modeled $D$ from different layer thicknesses and rainfall intensities reported in Sect. 3.1.

There were a number of reasons why the model did not perform well in the case of grass and woodchips. Massman (1983) suggested that the drainage function is important in the Rutter model, but the empirical representation of $D$ in the Rutter model depends on factors such as canopy structure 

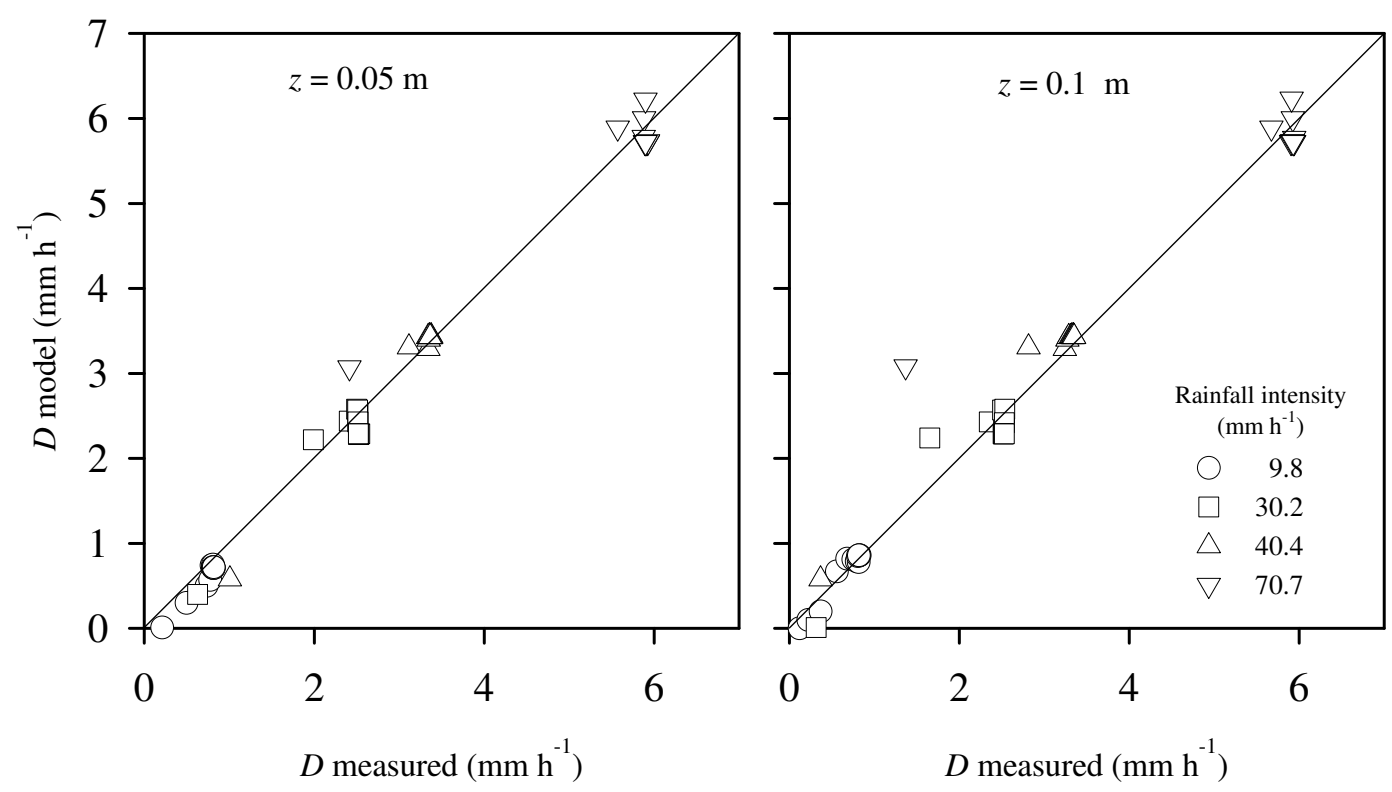

Fig. 8. Relationship between observed values of drainage ( $D$ measured) and its estimates using the model $\ln (D)=k+b C,(D$ model). Data corresponds to layers of poplar leaves.

and rainfall intensity and if storage is overestimated may lead to overestimation of interception loss. As with many other choices in developing models and parameterizations, the actual choice of the form of this dependence is a matter of (physically based) mathematical convenience. It was possible that another function will better fit the woodchips data as Pitman (1989) demonstated. At the moment we propose that a model that considers adsorption and absorption by canopies surfaces will be more suitable. A model for woodchips would be more complex because the physical structure of the material changes after wetting and it is not completely recovered after drying.

We believe that the presented information was adequate regarding the uniqueness of the estimated drainage parameters of litter layers. Even if the distance between mulch foliage elements may be small enough to retain water by surface tension, they do not form a connected network and cannot allow water movement by capillarity. The only possible transfer of liquid water is the penetration of rain through the gaps or the dripping of intercepted rain on the litter layer elements (Bussiere and Cellier, 1994). The gaps between the elements of poplar leaves and fresh grass were considered big enough to allow for this assumption and consider the litter layer as a soil with big pores. Drying and wetting soil-water characteristic curves are affected by soil density and grain size distribution and therefore, a coarse-grained soil has a lower air-entry value, residual matric suction and less total hysteresis than a fine-grained soil.

\subsection{Implications}

Human activity influences the hydrologic cycle by using and controlling soil and vegetation. Particularly, the impact of forest clearing has been and continues to be profound. Alternatively, harvesting non wood forest products is considered a strategy for sustainable development of low income communities. Among these products, forest litter is important because contributes to cash economy (mainly as potting mix and mulch) and also because it meets daily and seasonal needs (livestock feed, fuel, fertilizer, among others). However, the increased economic significance may result in destructive harvesting and deterioration of the environment.

Forested areas provide alternative valuable ecosystem services such as carbon sequestration, water infiltration and filtration, soil erosion control and biodiversity. These values are generally attributed to the tree canopy but the forest floor also may contribute substantially. By measuring litter fall mass $\left(\mathrm{Mgha}^{-1}\right)$, and knowing the storage per unit of mass and area, is possible to determine storage of a given plot without adjustment for layer thickness -assuming that the poplar litter layer is homogeneous. For example, GuevaraEscobar et al. (2007) reported a $3.1 \mathrm{Mg} \mathrm{ha}^{-1}$ litter fall during the autumn months in a site with mature poplar planted at 37 stems per hectare. This amount of litter would have a $C_{\min }$ of $0.6 \mathrm{~mm} \mathrm{~kg}^{-1} \mathrm{~m}^{-2}$ (Fig. 4) and represent $60 \%$ of the poplar canopy storage in full leaf (Guevara-Escobar et al., 2000). Because silvopastoral plantings advocate low stocking densities, then it would be likely that the storage of leaf litter to be in the range of $0.2-0.6 \mathrm{~mm}$, assuming a uniform leaf litter distribution on the landscape. 
Leaf litter, represented by the values of the drainage and storage parameters determined here are important to better understand and model the role of vegetation in the hydrological cycle. Current hydrological models are approximations of the catchment process; they are not complete because the knowledge of the process is not detailed. Physical based mathematical models describe the characteristics of the cachtement using a number of parameters but the practical use of this type of model requires experimental measurements and the characterization of hydraulic properties. Often, numerical solutions or lumped conceptual models with low input data requirements are used, because a parameterization of physically-based models is not feasible with the available data.

We focused on recently senesced poplar leaves because their presence in the system is associated with litter fall and this is an understandable and relatively predictable phenomenon. The properties of litter accumulated in the floor are more complex and deserve further study, but this study should involve the effect of decay among others. This is complicated with the incorporation of organic mater into the mineral soil and the consequent change of soil hydrological properties. Here, we presented an initial and simplified approximation to this problem with the examination of drainage and storage of poplar layers with an underlying soil matrix but more research is needed in this area.

\section{Conclusions}

This study confirms previous reports of increased maximum storage proportional to increased rainfall intensity. However, minimum storage remained constant with respect to increasing rainfall intensity. Lateral movement of water within litter layers and the effect of the soil matrix interface deserve further research. Drainage data from a near saturated soil matrix indicated that the presence of a poplar leaf layer dampens drainage rate, but total drainage was similar with or without a poplar leaf layer. This effect was related to rainfall intensity: at 9.8 and $70.9 \mathrm{~mm} \mathrm{~h}^{-1}$ there was little influence on drainage, but at intermediate intensities (30.2 and $40.4 \mathrm{~mm} \mathrm{~h}^{-1}$, drainage rate was lower and lagged in time when compared to drainage from the soil matrix only.

The Rutter model could be useful because our modeling demonstrated that the drainage and percolation parameters were able to predict drainage from layers of recently senesced poplar leaves regardless of the rainfall intensity within the window from 9.8 to $70.9 \mathrm{~mm} \mathrm{~h}^{-1}$. For other materials this representation was less accurate. The results involving an underlying soil matrix suggests that transient drainage modeling would also be needed.
Acknowledgements. The authors would like to thank all their colleagues and students at Universidad Autonoma de Queretaro who contributed to this study. Resources for the realization of this study were given by the CONACYT (Consejo Nacional de Ciencia y Tecnologia Mexico) grant QRO-2004-C01-17.

Edited by: H. H. G. Savenije

\section{References}

Balazs, A.: Interzeptions-verdunstung des waldes im winterhalbjahr als bestimmungsgrobe des nutzbaren wasserdargebots, Beitrage zur Hydrologie - Sonderheft, 4, 79-102, 1982.

Bristow, K. and Campbell, G.: Simulation of heat and moisture transfer through a surface residue-soil system, Agric. For. Meteorol., 36, 193-214, 1986.

Brown, V. A., McDonnell, J. J., Burns, D. A., and Kendall, C.: The role of event water, a rapid shallow flow component, and catchment size in summer stormflow, J. Hydrol., 217, 171-190, 1999.

Bussiere, F. and Cellier, P.: Interception de la pluie par un mulch de feuilles de canne a sucre (Saccharum officinarum): utilisation d'un dispositif de mesure automatise pour le test d'un modele, Agronomie, 13, 35-43, 1993.

Bussiere, F. and Cellier, P.: Modification of the soil temperature and water content regimes by a crop residue mulch-experiment and modelling, Agric. For. Meteorol., 68, 1-28, 1994.

Calder, I.: A stochastic model of rainfall interception, J. Hydrol., 89, 65-71, 1986.

Carlyle-Moses, D.: A Reply to R. Keims Comment on "Measurement and modeling of growing-season canopy water fluxes in a mature mixed deciduous forest stand, southern Ontario", Canada, Agric. For. Meteorol., 124, 281-284, 2004.

Crockford, R. and Richardson, D.: Partitioning of rainfall into throughfall, stemflow and interception: effect of forest type, ground cover and climate, Hydrol. Process., 14, 2903-2920, 2000.

Findeling, A., Ruy, S., and Scopel, E.: Modeling the effects of a partial residue mulch on runoff using a physically based approach, J. Hydrol., 275, 49-66, 2003.

Gash, J.: An analytical model of rainfall interception by forests, Quart. J. Roy. Meteorol. Soc., 105, 43-55, 1979.

Gerrits, A. M. J., Savenije, H. H. G., Hoffmann, L., and Pfister, L.: New technique to measure forest floor interception - an application in a beech forest in Luxembourg, Hydrol. Earth Syst. Sci., 11, 695-701, 2007, http://www.hydrol-earth-syst-sci.net/11/695/2007/.

Gonzalez-Sosa, E., Braud, I., Thony, J. L., Vauclin, M., Bessemoulin, P., and Calvet, J. C.: Heat and water exchanges of fallow covered with a plant-residue mulch layer: a modelling study using three years MUREX data set, J. Hydrol., 244, 119-136, 2001.

Guevara-Escobar, A., Edwards, W. R. N., Morton, R. H., Kemp, P. D., and Mackay, A. D.: Tree water use and rainfall partitioning in a mature poplar-pasture system, Tree Physiol., 20, 97-106, 2000.

Guevara-Escobar, A., Kemp, P. D., Mackay, A. D., and Hodgson, J.: Pasture production and composition under poplar in a hill environment in New Zealand, Agrofor. Sys., 69, 199-213, 2007. 
Helvey, J. D. and Patric, J. H.: Canopy and litter interception of rainfall by hardwood of eastern United States, Water Resour. Res., 1, 193-206, 1965.

Horton, R.: Rainfall interception, Monthly Weather Rev., 47, 603623, 1919.

Huber, A. M. and Oyarzun, C. E.: Redistribución de las precipitaciones de un bosque siempreverde del sur de Chile, Turrialba, 42, 192-199, 1992.

Keim, R. F.: Comment on "Measurement and modeling of growingseason canopy water fluxes in a mature mixed deciduous forest stand, southern Ontario, Canada", Agric. Forest Meteorol., 124, 277-279, 2004.

Keim, R. F. and Skaugset, A. E.: A linear system model of dynamic throughfall rates beneath forest canopies, Water Resour. Res., 40, W05208, doi:10.1029/2003WR002875, 2004.

Keim, R. F., Skaugset, A. E., and Weiler, M.: Temporal persistence of spatial patterns in throughfall, J. Hydrol., 314, 263-274, 2005.

Keim, R. F., Skaugset, A. E., and Weiler, M.: Storage of water on vegetation under simulated rainfall of varying intensity, Adv. Water Res., 29, 974-986, 2006.

Kelliher, F., Whitehead, D., and Pollock, D.: Rainfall interception by trees and slash in a young Pinus radiata D. Don stand, J. Hydrol., 131, 187-204, 1992.

Klaassen, W., Bosveld, F., and de Water, E.: Water storage and evaporation as constituents of rainfall interception, J. Hydrol., 212-213, 36-50, 1998.

Massman, W.: The derivation and validation of a new model for the interception of rainfall by forests, Agric. Met., 28, 261-286, 1983.

Nanko, K., Hotta, N., and Suzuki, M.: Evaluating the influence of canopy species and meteorological factors on throughfall drop size distribution, J. Hydrol., 329, 422-431, 2006.

Pitman, J. I.: Rainfall interception by bracken in open habitats relations between leaf area, canopy storage and drainage, J. Hydrol., 105, 317-334, 1989.

Putuhena, W. M. and Cordery, I.: Estimation of interception capacity of the forest floor, J. Hydrol., 180, 283-299, 1996.
Raat, K., Draaijers, G., Schaap, M., Tietema, A., and Verstraten, J.: Spatial variability of throughfall water and chemistry and forest floor water content in a Douglas fir forest stand, Hydrol. Earth Syst. Sci., 6, 363-374, 2002, http://www.hydrol-earth-syst-sci.net/6/363/2002/.

Rutter, A. J., Kershaw, K. A., Robbins, P. C., and Morton, A. J.: A predictive model of rainfall interception in forests. I. Derivation of the model from observations in a plantation of Corsican pine, Agric. Meteorol., 9, 367-384, 1971.

Sato, Y., Kumagai, T., Kume, A., Otsuki, K., and Ogawa, S.: Experimental analysis of moisture dynamics of litter layers - the effects of rainfall conditions and leaf shapes, Hydrol. Process., 18, 3007-3018, 2004.

Steel, R. G. D. and Torrie, J. H.: Principles and Procedures of Statistics: A Biometrical Approach, McGraw-Hill, New York, NY, 1980.

Sutherland, R. A. and Ziegler, A. D.: Hillslope runoff and erosion as affected by rolled erosion control systems: A field study, Hydrol. Process., 20, 2830-2855, 2006.

Tobon-Marin, C., Bouten, I. W., and Dekker, S.: Forest floor water dynamics and root water uptake in four forest ecosystems in northwest Amazonia, J. Hydrol., 237, 169-183, 2000.

Vrugt, J. A., Dekker, S. C., and Bouten, W.: Identification of rainfall interception model parameters from measurements of throughfall and forest canopy storage, Water Resour. Res., 39, 1251, doi: 10.1029/2003WR002013, 2003.

Waring, R., Rogers, J., and Swank, W.: Water Relations and Hydrologic Cycles, chap. 4, Dynamic Properties of Forest Ecosystems, Cambridge University Press, 205-264, 1980.

Weiler, M. and McDonnell, J.: Virtual experiments: a new approach for improving process conceptualization in hillslope hydrology, J. Hydrol., 285, 3-18, 2004.

Wiersum, K.: Surface erosion under various tropical agroforestry systems, in: Effects of Forest Land Use on Erosion and Slope Stability, edited by: O'Loughlin, O. and Pearce, A., IUFRO, 231-239, 1984.

Zeng, N., Shuttleworth, J. W., and Gash, J. H. C.: Influence of temporal variability of rainfall on interception loss. Part I. Point analysis, J. Hydrol., 228, 228-241, 2000. 